\title{
Rocuronium pharmacokinetic-pharmacodynamic relationship under stable propofol or isoflurane anesthesia
}

\author{
[La relation pharmacocinétique-pharmacodynamique du rocuronium pendant \\ une anesthésie avec propofol ou isoflurane]
}

Alexandrina Dragne MD, ${ }^{*}$ France Varin BPHARM PhD,${ }^{*}$ Benoit Plaud MD, $\dagger$ François Donati PhD MD FrCPC $\dagger$

Purpose: To compare the pharmacokinetics, pharmacodynamics and the concentration-effect relationship of rocuronium in patients under stable propofol or isoflurane anesthesia.

Methods: Ten patients were randomized to receive fentanyl, propofol and nitrous oxide (60\%) or fentanyl, thiopental, isoflurane ( $1.2 \%$ end-tidal concentration) and nitrous oxide (60\%). To obtain good intubation conditions and maintain adequate muscle relaxation during surgery, patients received two bolus doses of rocuronium: $0.5 \mathrm{mg} \cdot \mathrm{kg}^{-1}\left(1.7 \times \mathrm{ED}_{95}\right)$ at induction followed one hour later by $0.3 \mathrm{mg} \cdot \mathrm{kg}^{-1}\left(\mathrm{I} \times \mathrm{ED}_{95}\right)$. Arterial blood samples were obtained over six hours after the second bolus dose. Plasma concentrations of rocuronium were measured using high pressure liquid chromatography. Muscle twitch tension was monitored by mechanomyography for the two doses. Pharmacokinetic and pharmacodynamic parameters were determined.

Results: No differences in rocuronium pharmacokinetic parameters were observed between both groups. After the second bolus, clinical duration was $20 \pm 6 \mathrm{~min}$ in the propofol group vs $39 \pm 8$ $\mathrm{min}$ in the isoflurane group $(P<0.05)$. The effect compartment concentration corresponding to $50 \%$ block, $\mathrm{EC}_{50}$, was higher under propofol anesthesia: 1008 vs $592 \mu \mathrm{g} \cdot \mathrm{L}^{-1}(P<0.05)$.

Conclusion: Rocuronium body disposition is similar under stable propofol or isoflurane anesthesia. In contrast to isoflurane, propofol does not prolong the neuromuscular block. Therefore, the potentiating effect of isoflurane is of pharmacodynamic origin only, as explained by an increased sensitivity at the neuromuscular junction. In contrast with isoflurane anesthesia where the dose of rocuronium has to be decreased under stable conditions, no dose adjustment is required under propofol anesthesia.
Objectif : Comparer la pharmacocinétique, la pharmacodynamie et la relation concentration-effet du rocuronium chez les patients sous anesthésie équilibrée avec propofol ou isoflurane.

Méthodes : Dix patients ont été randomisés pour recevoir fentanyl, propofol et oxide nitreux (60\%) ou fentanyl, thiopental, isoflurane (I,2 $\%$ concentration télé-expiratoire) et oxyde nitreux (60\%). Pour obtenir de bonnes conditions d'intubation et maintenir une relaxation musculaire adéquate pendant la chirurgie, les patients ont reçu deux doses de rocuronium : $0,5 \mathrm{mg} \cdot \mathrm{kg}^{-1}\left(1,7 \times E D_{95}\right)$ à l'induction, suivi de $0,3 \mathrm{mg} \cdot \mathrm{kg}^{-1}$ $\left(I \times E D_{95}\right)$ une heure plus tard. Des échantillons sanguins artériels ont été prélevés jusqu'à six heures après l'administration du deuxième bolus et les concentrations plasmatiques du rocuronium mesurées par chromatographie liquide haute performance (CLHP). La fonction neuromusculaire a été enregistrée pour les deux doses. On a déterminé les paramètres pharmacocinétiques et pharmacodynamiques.

Résultats : Aucune différence n'a été observée entre les deux groupes pour les paramètres pharmacocinétiques. Après la deuxième dose, la durée clinique a été de $20 \pm 6$ min pour le groupe propofol comparativement à $39 \pm 8$ min pour le groupe isoflurane $(P<0,05)$. La concentration dans le compartiment effet correspondant à $50 \%$ de blocage neuromusculaire, la $E C_{50}$, a été plus élevée sous anesthésie avec propofol: 1008 vs $592 \mu \mathrm{g} \cdot \mathrm{L}^{-1}(P<0,05)$.

Conclusion : L'élimination corporelle du rocuronium est semblable pour les deux types d'anesthésie. Contrairement à l'isoflurane, le propofol ne prolonge pas le blocage neuromusculaire. Par conséquent, l'effet de potentialisation de l'isoflurane serait uniquement d'origine pharmacodynamique et s'expliquerait par une augmentation de la sensibilité au niveau de la jonction neuromusculaire. Contrairement à l'isoflurane qui nécessite une diminution de la dose de rocuronium dans des conditions d'anesthésie équilibrée, aucun ajustement n'est nécessaire sous anesthésie avec propofol.

De la Faculté de pharmacie, ${ }^{*}$ Université de Montréal, et du Département d'anesthésiologie,† Université de Montréal et Centre Hospitalier de l'Université de Montréal (Hôtel-Dieu), Montréal, Québec, Canada.

Address correspondence to: Dr. France Varin, Faculté de Pharmacie, Université de Montréal, C.P. 6128, succursale Centre-ville,

Montréal, Quebec H3C 3J7, Canada. Phone: 514-343-7016; Fax: 514-343-5735; E-mail: france.varin@umontreal.ca.

This study was supported by the Canadian Institutes of Health Research.

Accepted for publication October 2, 2001.

Revision accepted November 19, 2001. 
I SOFLURANE decreases the requirement for non-depolarizing neuromuscular blocking agents. Propofol and isoflurane are largely used in today's anesthesia. For rocuronium, the doseresponse curve is shifted to the left under isoflurane anesthesia, i.e., a given dose produces more blockade. ${ }^{1}$ For vecuronium, the plasma concentration required for $90 \%$ blockade is less under stable isoflurane anesthesia compared to fentanyl anesthesia. ${ }^{2}$ In these studies, the control group consisted of patients receiving a nitrousnarcotic anesthetic. In contrast, propofol does not seem to potentiate neuromuscular blockade, although no clear evidence has been provided yet.

These findings suggest that part of the interaction between potent vapours and neuromuscular blocking drugs might be explained by an increased sensitivity at the neuromuscular junction, (i.e., a pharmacodynamic origin). However, at least some of the changes could be explained by a change in pharmacokinetics. Indications that changes in pharmacokinetics may occur under propofol anesthesia were given when the results of two studies conducted by our group were compared. The clearance $(\mathrm{Cl})$ and the volume of distribution of doxacurium in 20-60-yr-old patients under $\mathrm{N}_{2} \mathrm{O}$-propofol anesthesia ${ }^{3}$ were significantly lower than those previously observed in either young $(20-40$-yr-old $)$ or in elderly patients, $(60-80$-yr-old $)$ when the same muscle relaxant was administered shortly after the start of isoflurane administration. ${ }^{4}$ The historical nature of the comparison and the difference in methodology (arterial $v s$ venous sampling) could not explain the large difference observed (approximately $50 \%)$. In addition, any effect of isoflurane on the neuromuscular junction is expected to take time to be manifest, as the equilibrium with muscle tissue is not immediate. ${ }^{5}$ Based on these data, we hypothesized that the different hemodynamic effects of propofol and isoflurane could be responsible for the pharmacokinetic changes and that these changes could be more pronounced under steady-state conditions.

The purpose of the present study was to compare, in two parallel groups, the pharmacokinetics, pharmacodynamics and the concentration-effect relationship of a commonly used neuromuscular blocking drug, rocuronium, under propofol or isoflurane anesthesia. These comparisons were made after the volatile anesthetic had time to equilibrate with muscle, that is after one hour.

\section{Methods}

After obtaining approval of the Hospital Ethics Committee and written informed consent, ten patients were included in this protocol, five patients for each group. In the previous studies considered for our working hypothesis, the differences between doxacurium pharmacokinetic parameters (clearance and volume of distribution) under propofol and isoflurane anesthesia were of the order of $50 \%$. A difference of $40 \%$ was considered clinically significant, and the number of patients in the present study was calculated accordingly. All subjects were male patients ASA physical status I or II, aged between 20-65 yr, with no neuromuscular, renal, hepatic, cardiac or respiratory diseases, and scheduled for elective surgery of at least two hours duration for which the insertion of an arterial cannula was justified on clinical grounds. Patients taking medications known to interfere with neuromuscular function were excluded. These drugs included aminoglycosides, anticonvulsants, calcium channel antagonists, digitalis, antidepressants, diuretics and corticosteroids.

The patients were not premedicated. On arrival in the operating room, a 20 -gauge cannula was inserted into the radial artery under local anesthesia. Monitoring included electrocardiography, continuous blood pressure determination, pulse oximetry, and body temperature. Inspired and expired carbon dioxide oxygen, nitrous oxide and inhalational vapour concentration were measured using a gas monitor (Hewlett-Packard M 1026A, Philipps, Boeblingen, Germany). Patients were randomly assigned to either the propofol or isoflurane group. In the propofol group $(n=5)$, anesthesia was induced with fentanyl 2-5 $\mu \mathrm{g} \cdot \mathrm{kg}^{-1}$ and propofol $1.5-2.5 \mathrm{mg} \cdot \mathrm{kg}^{-1}$ and maintained with propofol $10-15 \mathrm{mg} \cdot \mathrm{kg}^{-1} \cdot \mathrm{hr}^{-1}$ and $60 \%$ nitrous oxide in oxygen. In the isoflurane group $(n=5)$, anesthesia was induced with fentanyl $2-5 \mu \mathrm{g} \cdot \mathrm{kg}^{-1}$ followed by thiopental 2-7 $\mathrm{mg} \cdot \mathrm{kg}^{-1}$ and maintained with isoflurane $1.2 \%$, end-tidal concentration and $60 \%$ nitrous oxide in oxygen, supplemented with fentanyl. Neuromuscular block was measured by mechanomyography in the arm contralateral to the radial artery cannula. The ulnar nerve was stimulated at the wrist, every ten seconds, with single supramaximal twitches $(0.2 \mathrm{msec}$ at $0.1 \mathrm{~Hz}$ ) via surface electrodes. The resultant force of contraction of the adductor pollicis was measured using a force transducer (Grass FT-10, Grass Instruments Co., Quincy, MA, USA).

Neuromuscular function was monitored once the patient lost consciousness and throughout anesthesia, until recovery from the last dose of rocuronium. After induction of anesthesia and stabilization of the muscle response to peripheral nerve stimulation, an iv bolus of rocuronium bromide $0.5 \mathrm{mg} \cdot \mathrm{kg}^{-1}$ was injected over two seconds. When maximum depression of the twitch response was observed, the trachea was intubated and mechanical ventilation begun. In the five 
minutes prior to intubation, the lungs were manually ventilated. The first bolus was necessary to insure good intubating conditions and muscle relaxation during surgery. A period of one hour was judged adequate to obtain reasonable equilibration between volatile anesthetic and muscle tissue. The second bolus of rocuronium bromide $0.3 \mathrm{mg} \cdot \mathrm{kg}^{-1}$ was administered one hour after the first dose to establish the concentration- effect relationship. No other neuromuscular blocking agent was given.

An arterial blood sample was taken, into a heparinized tube, before the first bolus of rocuronium. To measure the residual plasma concentration from the first dose, another sample was drawn immediately before the injection of the second bolus of rocuronium. After administration of the second bolus, arterial blood samples were collected every ten seconds, during the first two minutes ${ }^{6}$ and then at three, five, seven, ten, 20, 30, 40, $50 \mathrm{~min}$ and at one, two, three, four, five, six hours. The time assigned to each sample was the midpoint between the beginning and the end of the collection time. To avoid rocuronium ex vivo degradation, samples were kept on an ice-bath for a few minutes and then centrifuged. Plasma was acidified to $\mathrm{pH} 4$ with $12 \mu \mathrm{L}$ of $2 \mathrm{M}$ sulfuric acid per $\mathrm{mL}$ of plasma, then frozen on dry ice. Samples were stored at $-70^{\circ} \mathrm{C}$ until assayed. Plasma concentrations of rocuronium and its metabolite, 17-desacetylrocuronium, were determined using a high-performance liquid chromatographic assay coupled with electrochemical detection after slight modifications. ${ }^{7}$ Briefly, the analytes were extracted using a solid- phase extraction cartridges (Bond Elut $\mathrm{C}_{1}$ ) and mean recoveries of $97 \%$ for rocuronium and $98 \%$ for its metabolite were obtained. The lower limit of quantitation was 7.8 $\mathrm{ng} \cdot \mathrm{mL}^{-1}$ for rocuronium and $3.9 \mathrm{ng} \cdot \mathrm{mL}^{-1}$ for the metabolite with a linearity up to 2000 and 1000 ng. $\mathrm{mL}^{-1}$, respectively. Plasma concentrations higher than the validated range were diluted with blank plasma. The accuracy of the assay was $102.4 \%$ for rocuronium and $108.2 \%$ for its metabolite. The inter-day precision gave a bias of less than 4.4 and $7.4 \%$, respectively.

In our experience, the interpatient variability of pharmacokinetic parameters for neuromuscular blockers is $25 \% .^{3,4,6}$ For this reason a difference of at least $40 \%$ between both groups was considered to have a clinical significance. The sample size was estimated accordingly. The power of the study was 0.80 .

Results were expressed as mean values \pm standard deviation (SD). Student's t test pair-wise comparisons were made between the pharmacodynamic data obtained for each subject after the first and second dose. Comparisons between values obtained in the two groups were performed with a Student's test for unpaired data or with Mann- Whitney Rank Sum test. A $P$ value $<0.05$ was considered to indicate a statistically significant difference.

A three-compartment model with two iv bolus inputs (the first dose, $0.5 \mathrm{mg} \cdot \mathrm{kg}^{-1}$ and the second, 0.3 $\mathrm{mg} \cdot \mathrm{kg}^{-1}$ given one hour later) described better the plasma concentration-time profile than a two-compartment model. Goodness of fit was compared using the Akaike's information criterion. Pharmacokinetic analysis was based on iterative linear least square regression analysis using the computer program WinNonlin. Even though our design included an extensive sampling schedule over the first two minutes and thus a good characterization of the intravascular mixing phase, a parametric pharmacokinetic analysis was carried out for the following reasons. Rocuronium plasma concentration-time data were obtained for the second dose only, therefore, accurate estimation of pharmacokinetic parameters had to take into account the contribution of the first dose. Also, a parametric model allowed simulations of rocuronium plasma concentrations after the first bolus dose in each patient (see below). The residual plasma concentrations prior to the second dose were measured and used to validate the simulated concentration after this time point. For optimal modelling, concentration points immediately after the intravascular mixing phase (i.e., approximately $50 \mathrm{sec}$ ) and all other points thereafter were included in the analysis. With vecuronium, this approach has previously been shown to yield similar pharmacokinetic parameters $\left(\mathrm{Vd}_{\mathrm{ss}}, \mathrm{Cl}\right)$ as a non compartmental analysis of the whole data set. ${ }^{6}$

Neuromuscular block was calculated as the percentage twitch height depression compared with the baseline value measured just before the first bolus administration. The onset time represents the time between injection of rocuronium and maximum blockade (peak effect), defined as the point where $\mathrm{Tl}$ was stable for the three consecutive responses. Clinical duration was the time between injection and recovery of twitch height to $25 \%$ of its control value. Recovery index, or the time between 25 and $75 \%$ twitch height recovery, was also measured. These pharmacodynamic parameters were calculated for the first and for the second bolus doses.

The concentration-effect relationship analysis (PKPD analysis) was carried out only for the second dose including the intravascular mixing phase. A non-parametric link model was used to minimize the area comprised between the two limbs of the plasma concentration-effect hysteresis and to derive the equilibrium rate constant between the central and effect compartments $\left(\mathrm{k}_{\mathrm{eo}}\right)$. This model required the input of 


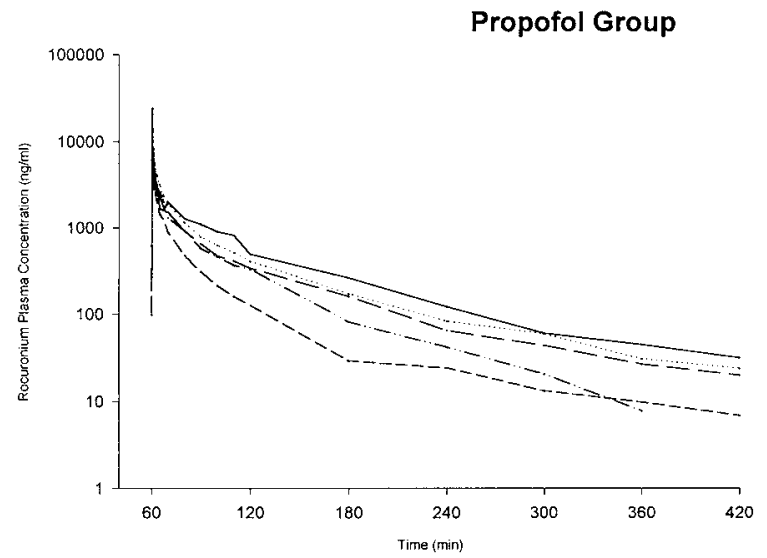

Isoflurane Group

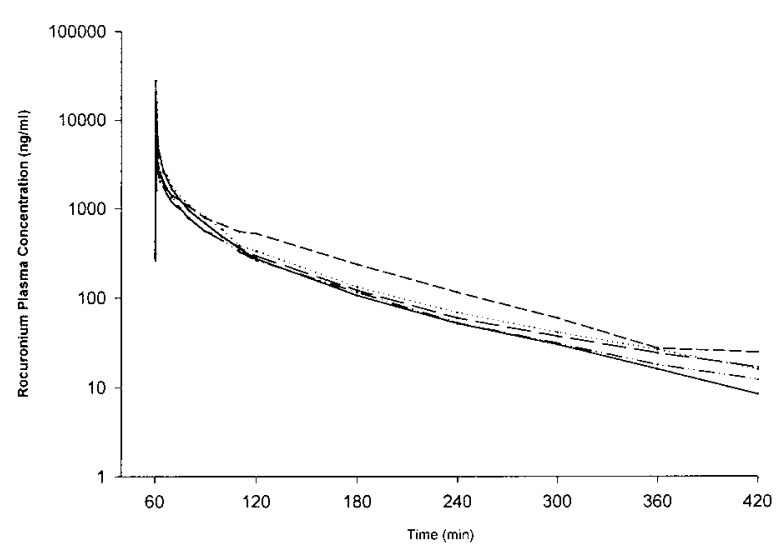

FIGURE 1 Plasma concentrations of rocuronium after the administration of a second dose of $0.3 \mathrm{mg} \cdot \mathrm{kg}^{-1}$, at $60 \mathrm{~min}$, under propofol or isoflurane anesthesia.

time, its corresponding plasma concentration and percentage of block. ${ }^{8}$ A sigmoid Emax model was assumed and the effective compartment concentration associated with $50 \%$ drug effect $\left(\mathrm{EC}_{50}\right)$ and the slope of the sigmoidal curve $(\gamma)$ were estimated, as described before. ${ }^{3}$ A slight modification was made to the program to take into account the residual effect compartment concentration at the time of the second dose administration. ${ }^{9}$ This residual concentration was obtained by performing an analysis of the concentration-effect relationship (PK-PD analysis) on the simulated plasma concentrations and the observed block at different times after the first bolus. Such an approach was previously validated in a study with atracurium
TABLE I Pharmacokinetic parameters of rocuronium bromide, following a second $i v$ bolus of $0.3 \mathrm{mg} \cdot \mathrm{kg}^{-1}$ under propofol or isoflurane anesthesia

\begin{tabular}{lll}
\hline Parameters & Propofol $(n=5)$ & Isoflurane $(n=5)$ \\
\hline $\mathrm{A}\left(\mathrm{ng} \cdot \mathrm{mL}^{-1}\right)$ & $5987 \pm 2175$ & $5711 \pm 1701$ \\
$\mathrm{~B}\left(\mathrm{ng} \cdot \mathrm{mL}^{-1}\right)$ & $1488 \pm 657$ & $1653 \pm 405$ \\
$\mathrm{C}\left(\mathrm{ng} \cdot \mathrm{mL}^{-1}\right)$ & $145 \pm 52$ & $197 \pm 103$ \\
$\alpha\left(\mathrm{min}^{-1}\right)$ & $0.5562 \pm 0.2186$ & $0.5982 \pm 0.1489$ \\
$\beta\left(\mathrm{min}^{-1}\right)$ & $0.0470 \pm 0.0254$ & $0.0498 \pm 0.0075$ \\
$\gamma\left(\mathrm{min}^{-1}\right)$ & $0.0080 \pm 0.0022$ & $0.0088 \pm 0.0013$ \\
$\mathrm{t}_{1 / 2} \alpha(\mathrm{min})$ & $1.68 \pm 1.38$ & $1.17 \pm 0.30$ \\
$\mathrm{t}_{1 / 2} \beta(\mathrm{min})$ & $18.46 \pm 9.89$ & $13.9 \pm 2.1$ \\
$\mathrm{t}_{1 / 2} \gamma(\mathrm{min})$ & $86.62 \pm 23.24$ & $77.06 \pm 9.25$ \\
$\mathrm{Cl}\left(\mathrm{mL} \cdot \mathrm{kg}^{-1} \cdot \mathrm{min}^{-1}\right)$ & $4.37 \pm 1.56$ & $4.09 \pm 0.64$ \\
$\mathrm{~V}_{\mathrm{c}}\left(\mathrm{mL} \cdot \mathrm{kg}^{-1}\right)$ & $38 \pm 15$ & $35 \pm 9$ \\
$\mathrm{~V}_{\mathrm{ss}}\left(\mathrm{mL} \cdot \mathrm{kg}^{-1}\right)$ & $204 \pm 48$ & $187 \pm 52$ \\
$\mathrm{Cp}_{60}\left(\mathrm{ng} \cdot \mathrm{mL}^{-1}\right)$ & $323 \pm 182$ & $312 \pm 27$ \\
$\mathrm{C}_{\max }\left(\mathrm{ng} \cdot \mathrm{mL}^{-1}\right)$ & $18667 \pm 6246$ & $20860 \pm 4332$ \\
$\mathrm{~T}_{\max }(\mathrm{min})$ & $0.60 \pm 0.09$ & $0.70 \pm 0.22$ \\
\hline
\end{tabular}

Data are presented as mean \pm standard deviation. $\mathrm{A}, \mathrm{B}, \mathrm{C}=\mathrm{coeffi}-$ cients; $\alpha, \beta, \gamma=$ rate constants of the rapid distribution, slow distribution and elimination phase; $\mathrm{Cl}=$ total plasma clearance; $\mathrm{Cp}_{60}=$ residual plasma concentration before the second dose; $\mathrm{C}_{\max }=$ maximum plasma concentration; $t^{1 / 2} \alpha=$ rapid distribution half-life; $t_{1 / 2}$ $\beta=$ slow distribution half-life; $\mathrm{t}_{1 / 2} \gamma=$ elimination half-life; $\mathrm{T}_{\max }=$ time from injection to $\mathrm{C}_{\max } ; \mathrm{V}_{\mathrm{c}}=$ volume of central compartment; $\mathrm{V}_{\mathrm{ss}}=$ volume of distribution at steady state.

TABLE II Pharmacodynamic parameters of rocuronium bromide, following a first iv bolus of $0.5 \mathrm{mg} \cdot \mathrm{kg}^{-1}$ and a second bolus of $0.3 \mathrm{mg} \cdot \mathrm{kg}^{-1}$ under propofol or isoflurane anesthesia.

\begin{tabular}{lllll}
\hline & First bolus & \multicolumn{3}{l}{ Second bolus } \\
\hline Parameters & $\begin{array}{l}\text { Propofol } \\
(n=5)\end{array}$ & $\begin{array}{l}\text { Isoflurane } \\
(n=5)\end{array}$ & $\begin{array}{l}\text { Propofol } \\
(n=5)\end{array}$ & $\begin{array}{l}\text { Isoflurane } \\
(n=5)\end{array}$ \\
\hline $\begin{array}{l}\text { Onset (min) } \\
\text { Duration (min) }\end{array}$ & $5.0 \pm 1.6$ & $5.8 \pm 1.8$ & $2.4 \pm 0.5 \dagger$ & $1.8 \pm 0.3^{*}$ \\
$\begin{array}{l}\text { Recovery } \\
\text { index (min) }\end{array}$ & $12 \pm 2.9$ & $19 \pm 0.9$ & $20 \pm 6.3$ & $39 \pm 7.6^{*} \ddagger$ \\
Block $_{\max }(\%)$ & $94(86-100)$ & $97(94-100)$ & $97(86-100) 100$ \\
\hline
\end{tabular}

Data are presented as mean \pm standard deviation (neuromuscular block presented with range of responses in brackets); onset=time from end of injection to maximum block; duration=time from end of injection to $25 \%$ recovery of the twich height; recovery index=time from $25 \%$ to $75 \%$ recovery of the twitch height; Block

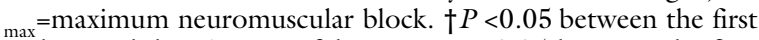
and second dose in propofol group; ${ }^{*} P<0.05$ between the first and second dose, in isoflurane group; $\ddagger P<0.05$ between propofol and isoflurane data for the second dose.

where two boluses were given one hour apart. ${ }^{9}$ To ensure a good modelling procedure, the same number of data points (6 to 9) was used for the onset and the recovery periods; for that purpose, simulated plasma concentrations corresponding to specific degrees of neuromuscular block were added, when necessary. 


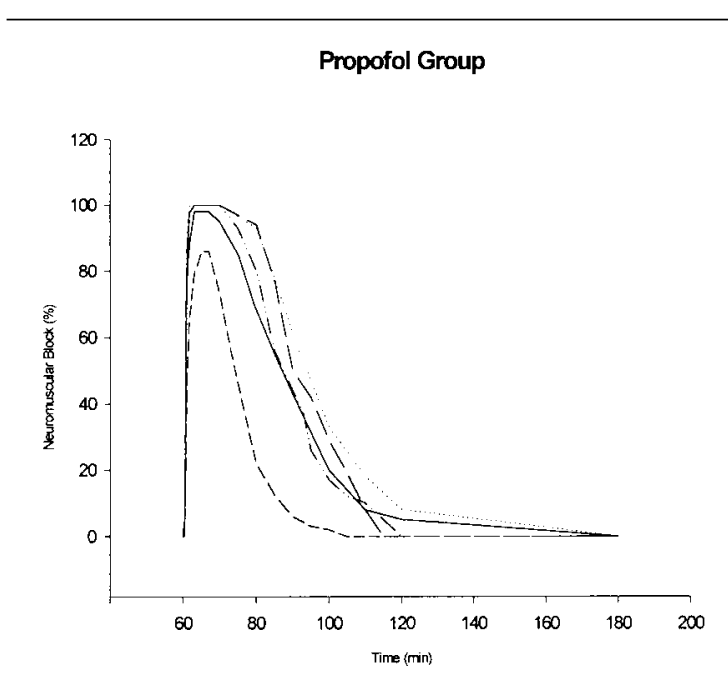

Isoflurane Group

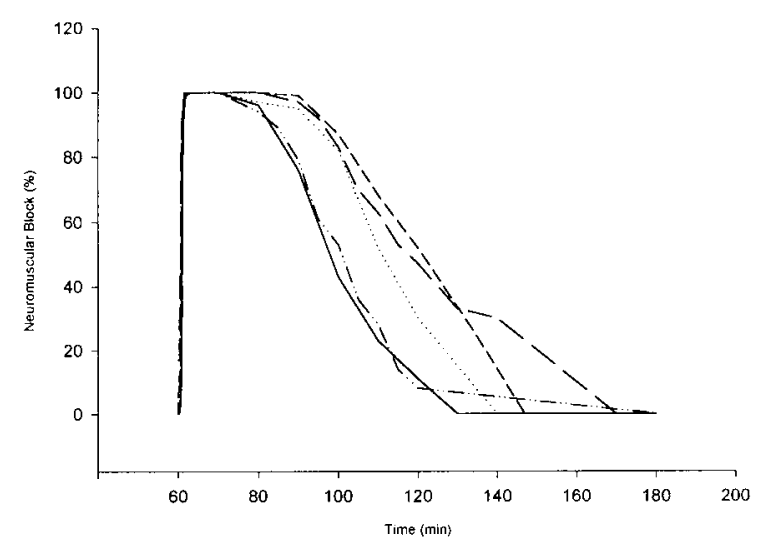

FIGURE 2 Neuromuscular block after the administration of a second dose of $0.3 \mathrm{mg} \cdot \mathrm{kg}^{-1}$ rocuronium, at $60 \mathrm{~min}$, under propofol or isoflurane anesthesia.

\section{Results}

The population under investigation consisted of ten male adults (ASA class I-II), five in each group, 64 to $92 \mathrm{~kg}$ in weight (isoflurane $79 \pm 10.8 \mathrm{~kg}$, propofol 74 $\pm 12.6 \mathrm{~kg}$ ), 1.58 to $1.77 \mathrm{~m}$ in height (isoflurane 1.73 $\pm 0.07 \mathrm{~m}$, propofol $1.66 \pm 0.08 \mathrm{~m}$ ) and 43 to $65-\mathrm{yr}-$ old (isoflurane $56 \pm 8.6 \mathrm{yr}$, propofol $58 \pm 4.3 \mathrm{yr}$ ), undergoing various types of surgery with a duration from two to $5.5 \mathrm{hr}$ (isoflurane $2.9 \mathrm{l} \pm 1.09 \mathrm{hr}$, propofol $3.38 \pm 1.4 \mathrm{hr}$ ). In the propofol group, surgeries performed were: peripheral vascular procedures (2); total hip replacement; radical prostatectomy (2). In the isoflurane group surgeries were: peripheral vascular procedures (2); radical prostatectomy (3).
TABLE III Pharmacokinetic-pharmacodynamic parameters of rocuronium bromide, following a second bolus of $0.3 \mathrm{mg} \cdot \mathrm{kg}^{-1}$ under propofol or isoflurane anesthesia

\begin{tabular}{lll}
\hline Parameters & $\begin{array}{l}\text { Propofol } \\
(n=5)\end{array}$ & $\begin{array}{l}\text { Isoflurane } \\
(n=5)\end{array}$ \\
\hline $\mathrm{EC}_{50}\left(\mathrm{ng} \cdot \mathrm{mL}^{-1}\right)$ & $1008 \pm 195$ & $592 \pm 112^{*}$ \\
$\mathrm{k}_{\mathrm{eo}}\left(\mathrm{min}^{-1}\right)$ & $0.14 \pm 0.04$ & $0.09 \pm 0.02$ \\
$\gamma$ & $4.43 \pm 1.05$ & $4.04 \pm 0.44$ \\
$\mathrm{t}_{1 / 2} \mathrm{k}_{\mathrm{eo}}(\mathrm{min})$ & $5.15 \pm 1.29$ & $7.92 \pm 1.51$ \\
\hline
\end{tabular}

Data are presented as mean \pm standard deviation. $\gamma=$ slope of sig moidal curve; $\mathrm{EC}_{50}=$ concentration in the effect compartment related to $50 \%$ effect; $\mathrm{k}_{\mathrm{eo}}=$ equilibration rate constant between central and effect compartments; $\mathrm{t}_{1 / 2} \mathrm{k}_{\mathrm{eo}}=$ equilibrium half-life; * $P$ $<0.05$.

Rocuronium plasma concentration $v s$ time profiles are presented in Figure 1. The plasma concentrationtime curve following the intravascular mixing phase was best described by a triexponential equation. No significant differences were obtained between the pharmacokinetic parameters obtained in both groups (Table I). In addition, comparable values for rocuronium peak concentration and time were obtained. In all patients, the plasma levels of the 17-desacetyl metabolite were below the detection limit.

Individual raw data representing the neuromuscular block vs time profiles are presented in Figure 2. For the first dose of rocuronium $\left(0.5 \mathrm{mg} \cdot \mathrm{kg}^{-1}\right)$, onset time, clinical duration and recovery index were not significantly different between groups (Table II). After one hour, all patients had recovered to $100 \%$, except two patients of the isoflurane group in whom a residual block of 11 and $17 \%$ was noted. In contrast, after the second dose of rocuronium $\left(0.3 \mathrm{mg} \cdot \mathrm{kg}^{-1}\right)$, onset time was more rapid than after the first dose, under both types of anesthetic. Compared with the first dose, clinical duration after the second dose was longer in the isoflurane group while it remained unchanged in the propofol group (Table II). Clinical duration after the second dose was longer with isoflurane than with propofol anesthesia.

Parameters of the concentration-effect relationship (PK-PD parameters) derived for the second dose are shown in Table III. The $\mathrm{EC}_{50}$ was $40 \%$ less under isoflurane than under propofol anesthesia. There was no significant difference in the slope factor and the $\mathrm{k}_{\text {eo }}$ for the two groups.

\section{Discussion}

This study was designed to establish whether the pharmacokinetics or the pharmacodynamics of rocuronium were changed under stable propofol anesthesia 
compared with isoflurane anesthesia. No differences in the rocuronium pharmacokinetics were observed under propofol compared with isoflurane anesthesia. Our results indicate that the potentiation of rocuronium neuromuscular blockade by isoflurane (1 MAC) is of pharmacodynamic origin, as reflected by a $40 \%$ lower $\mathrm{EC}_{50}$ value when compared with propofol.

Our study was designed to evaluate the influence of two anesthetic agents, propofol and isoflurane, on the pharmacokinetic/pharmacodynamic relationship of a second dose of rocuronium bromide of $0.3 \mathrm{mg} \cdot \mathrm{kg}^{-1}$. A rocuronium bolus of $0.5 \mathrm{mg} \cdot \mathrm{kg}^{-1}$ was first administered after inducing anesthesia with either propofol or isoflurane. As isoflurane equilibrates with muscle tissue with a time constant of $80 \pm 26 \mathrm{~min},{ }^{5}$ a stabilization period of one hour was included before the second bolus. A longer time period would have been theoretically better but we wanted to complete the pharmacokinetic study before the end of the surgical procedure. A first dose of rocuronium after induction of anesthesia proved to be necessary to provide adequate muscle relaxation during surgery. This first dose was included in the pharmacokinetic and pharmacodynamic calculations.

Since the pharmacokinetic analysis had to be carried out on plasma concentrations obtained immediately before and after the second dose of rocuronium, a three-compartment model that considered both doses and the time of their administration was selected. Our results are consistent with previous reports where rocuronium pharmacokinetics under isoflurane $e^{1,10-12}$ and propofol-nitrous oxide anesthesia ${ }^{1}$ were studied using a three- compartment model after a $0.6 \mathrm{mg} \cdot \mathrm{kg}^{-1}$ bolus dose.

It was previously reported that the pharmacokinetics of a single dose of rocuronium given just after the induction of isoflurane and propofol anesthesia did not differ. ${ }^{1}$ In our study, we wanted to verify that there were no time- related changes in the pharmacokinetics of rocuronium by comparing both types of anesthesia under stabilized conditions. Our results confirm the lack of influence from the anesthetic technique.

In contrast to the pharmacodynamic results presented herein, a shorter onset time and a longer duration of neuromuscular block were reported after administration of a first bolus dose of $0.6 \mathrm{mg} \cdot \mathrm{kg}^{-1}$ of rocuronium under comparable anesthetic conditions. ${ }^{1,10,12,13}$ These differences could be explained by a larger dose or a different type of neuromuscular monitoring (train-of-four stimulation). Stimulus frequency has been shown to reduce the onset time for a given degree of neuromuscular block $^{14}$ while single twitch stimulation has been associated with a decreased sensitivity $\left(\mathrm{ED}_{90}\right.$ and $\left.\mathrm{ED}_{95}\right)$ compared with train-of-four stimulation. ${ }^{15}$

After the first dose of rocuronium, clinical duration and recovery index were not statistically different between propofol and isoflurane groups. For this dose, given just after the induction of anesthesia, the period of time for interaction with the volatile anesthetic was probably not long enough, and this most likely explains the lack of significant potentiating effect of isoflurane on the rocuronium-induced neuromuscular block.

Other authors demonstrated that, after a short five to ten minutes of exposure to the anesthetic agent, the potentiation of the neuromuscular blocking effect of rocuronium by isoflurane was not apparent. ${ }^{16,17}$ In contrast, some investigators have shown that the clinical duration of a first dose of rocuronium was longer under isoflurane compared with propofol anesthesia. ${ }^{1,18}$ This might have resulted from the type of stimulation used ${ }^{1}$ or the absence of nitrous oxide with propofol. ${ }^{18}$ Our results clearly indicate a longer clinical duration with isoflurane than with propofol after the second bolus dose. These findings are consistent with a longer exposure to the anesthetic.

The residual effect of the first dose at the effect site is apparent when one compares the pharmacodynamics of the first and the second doses in each group. In spite of giving less drug, mean onset time was shorter for the second bolus for both anesthetic techniques. Although clinical duration under propofol anesthesia was comparable to that of the first dose, it was markedly prolonged after the second dose under isoflurane anesthesia (39 vs $26 \mathrm{~min}$ ). This indicates that isoflurane had not had the time to equilibrate with muscle tissue when the first dose was given, which supports our hypothesis. Our results also suggest that there is no time-dependent interaction between propofol and rocuronium.

The concentration-effect relationship of rocuronium under nitrous oxide-narcotic anesthesia was previously studied after a $0.6 \mathrm{mg} \cdot \mathrm{kg}^{-1}$ bolus dose. ${ }^{19}$ Their mean $\mathrm{EC}_{50}$ value ( $\left.1220 \mathrm{ng} \cdot \mathrm{mL}^{-1}\right)$ was similar to that observed in our propofol group (1008 $\left.\mathrm{ng} \cdot \mathrm{mL}^{-1}\right)$. Others obtained a mean $\mathrm{EC}_{50}$ value of $823 \mathrm{ng} \cdot \mathrm{mL}^{-1}$ for an initial rocuronium dose of $0.5 \mathrm{mg} \cdot \mathrm{kg}^{-1}$ administered as a short infusion of $100 \mathrm{mg} \cdot \mathrm{kg}^{-1} \cdot \mathrm{min}^{-1}$ over five minutes, under propofol anesthesia without nitrous oxide. ${ }^{20}$ It seems reasonable to infer that the sensitivity of the neuromuscular junction is comparable under propofol and nitrous oxide-narcotic anesthesia.

Under isoflurane anesthesia, the muscle was found to be much more sensitive to the neuromuscular blocking agent as indicated by a lower $\mathrm{EC}_{50}$ value when com- 
pared with propofol anesthesia (592 vs $\left.1008 \mathrm{ng} \cdot \mathrm{mL}^{-1}\right)$. In agreement with our findings, a 35 to $40 \%$ reduction of the plasma concentrations required to maintain $50 \%$ block $\left(\mathrm{Cp}_{\mathrm{ss} 50}\right)$ was observed under isoflurane compared with propofol anesthesia (441 vs $1077 \mathrm{ng} \cdot \mathrm{mL}^{-1}$ ) when the neuromuscular response was measured at different infusion regimens. ${ }^{21}$

In conclusion, contrary to isoflurane anesthesia where the dose of rocuronium has to be decreased under stable anesthesia conditions, no dose adjustment is required under propofol anesthesia. This study also demonstrates that the potentiating effect of isoflurane is of pharmacodynamic origin and emphasizes the need for continuous monitoring of the patient's clinical response. Intravenous and volatile anesthetics are usually administered at the same time as the neuromuscular blocking agent in the clinical practice. In short surgical procedures (one hour or less) potentiation is probably not clinically important at this concentration of isoflurane and a second dose of rocuronium would not need to be adjusted. However, during long surgical procedures, an adjustment of the dose should be done to avoid the potentiating effect of isoflurane on the neuromuscular blocking drug. In contrast to propofol anesthesia, the clinical duration of a second dose of rocuronium is greatly increased under isoflurane anesthesia. According to this, maintenance doses of rocuronium employed under propofol anesthesia should be reduced by almost $50 \%$ when isoflurane is used as the anesthetic during surgical procedures of two hours or more. This may result in a net cost-saving. Conversely, anesthesia with propofol may provide a more predictable response for muscle relaxants.

\section{Acknowledgement}

The authors thank Johanne Couture for her technical assistance.

\section{References}

1 Van der Broek L, Wierda JMKH, Smeulers NJ, et al. Clinical pharmacology of rocuronium (Org 9426); study of the time course of action, dose requirement, reversibility and pharmacokinetics. J Clin Anesth 1994; 6: 288-96.

2 Cannon JE, Fahey MR, Castagnoli KP, et al. Continuous infusion of vecuronium: the effect of anesthetic agents. Anesthesiology 1987; 67: 503-6.

3 Zhu Y, Audibert G, Donati F, Varin F. Pharmacokinetic-pharmacodynamic modeling of doxacurium: effect of input rate. J Pharmacokinet Biopharm 1997; 25: 23-37.

4 Gariepy LP, Varin F, Donati F, Salib Y, Bevan DR.
Influence of aging on the pharmacokinetics and pharmacodynamics of doxacurium. Clin Pharmacol Ther 1993; 53: 340-7.

5 Yasuda N, Lockbart SH, Eger II EI, et al. Kinetics of desflurane, isoflurane, and halothane in humans. Anesthesiology 1991; 74: 489-98.

6 Ducharme J, Varin F, Bevan DR, Donati F. Importance of early blood sampling on vecuronium pharmacokinetic and pharmacodynamic parameters. Clin Pharmacokinet 1993; 24: 507-18.

7 Ducharme J, Varin F, Bevan DR, Donati F, Théorêt $\Upsilon$. High-performance liquid chromatography-electrochemical detection of vecuronium and its metabolites in human plasma. J Chromatogr 1992; 573: 79-86.

8 Unadkat JD, Bartha F, Sheiner LB. Simultaneous modeling of pharmacokinetics and pharmacodynamics with nonparametric kinetic and dynamic models. Clin Pharmacol Ther 1986; 40: 86-93.

9 Ducharme J, Varin F, Donati F. Pharmacokinetics and pharmacodynamics of a second dose of atracurium in anaesthetised patients. Clin Drug Invest 1995; 9 : 95-110.

10 Cooper RA, Mirakbur RK, Wierda JMKH, Maddineni $V R$. Pharmacokinetics of rocuronium bromide in patients with and without renal failure. Eur J Anaesth 1995; 12(Suppl.11): 43-4.

11 Szenobradszky J, Fisher DM, Segredo V, et al. Pharmacokinetics of rocuronium bromide (ORG 9426 ) in patients with normal renal function or patients undergoing cadaver renal transplantation. Anesthesiology 1992; 77: 899-904.

12 Magorian T, Wood P, Caldwell J, et al. The pharmacokinetics and neuromuscular effects of rocuronium bromide in patients with liver disease. Anesth Analg 1995; 80: 754-9.

13 Davis L, Jayarajah MJ, Toner CC, Flynn PJ. Evaluation of neuromuscular effects and antagonism of rocuronium bromide: a preliminary report. Eur J Anaesth 1995; 12(Suppl.11): 65-8.

14 Ali HH, Savarese JJ. Stimulus frequency and dose-response curve to d-tubocurarine in man. Anesthesiology 1980; 52: 36-9.

15 Cooper RA, Mirakhur RK, Elliot P, McCarthy GJ. Estimation of the potency of ORG 9426 using two different modes of nerve stimulation. Can J Anaesth 1992; 39: 139-42.

16 Lambalk LM, De Wit APM, Wierda JMKH, Hennis PJ, Agoston S. Dose-response relationship and time course of action of Org 9426. A new muscle relaxant of intermediate duration evaluated under various anaesthetic techniques. Anaesthesia 1991; 46: 907-11.

17 Lowry DW, Mirakbur RK, McCarthy GJ, Carroll MT, McCourt KC. Neuromuscular effects of rocuronium 
during sevoflurane, isoflurane, and intravenous anesthesia. Anesth Analg 1998; 87: 936-40.

18 Oris B, Crul JF, Vandermeersch E, Van Aken H, Van Egmond J, Sabbe MB. Muscle paralysis by rocuronium during halothane, enflurane, isoflurane, and total intravenous anesthesia. Anesth Analg 1993; 77: 570-3.

19 Khalil M, D'Honneur G, Duvaldestin P, Slavov V, De Hys C, Gomeni R. Pharmacokinetics and pharmacodynamics of rocuronium in patients with cirrhosis. Anesthesiology 1994; 80: 1241-7.

20 Pland B, Proost JH, Wierda JMKH, Barre J, Debaene B, Meistelman $C$. Pharmacokinetics and pharmacodynamics of rocuronium at the vocal cords and the adductor pollicis in humans. Clin Pharmacol Ther 1995; 58: 185-91.

21 Kansanaho M, Olkkola KT, Wierda JMKH. Doseresponse and concentration-response relation of rocuronium infusion during propofol-nitrous oxide and isoflurane-nitrous oxide anaesthesia. Eur J Anaesth 1997; 14: 488-94.

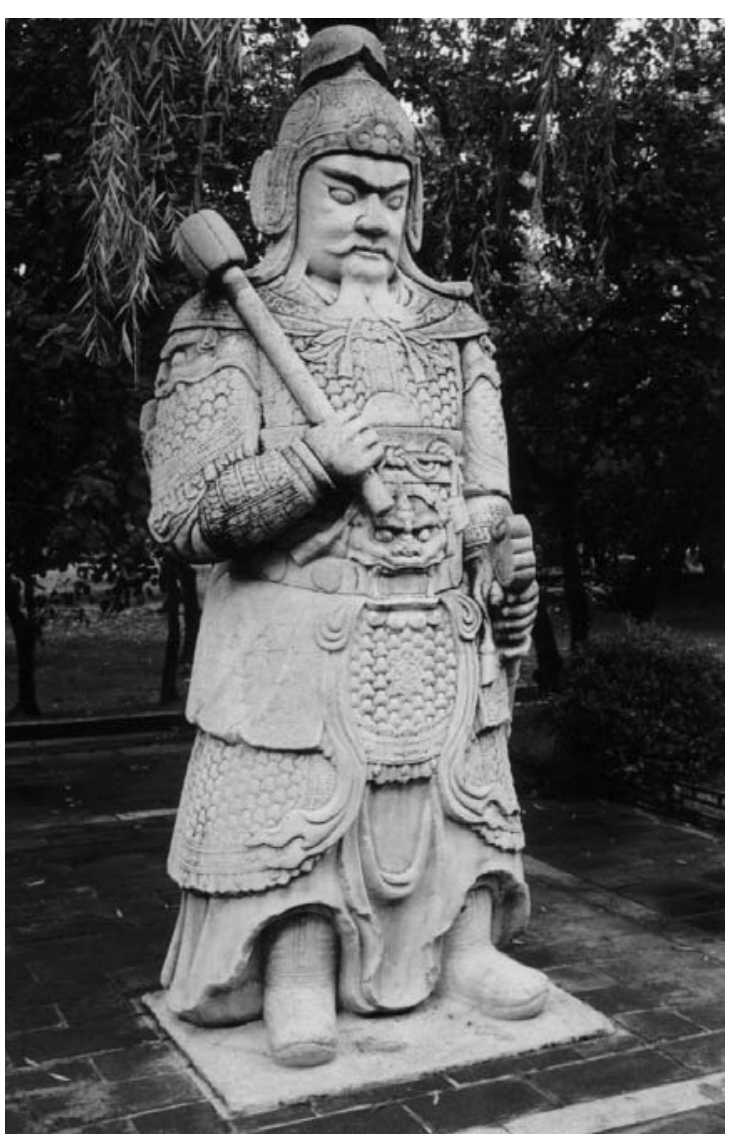

Warrior from the Ming dynasty tomb - Beijing 